\title{
De exemplarische Droogstoppel. Een eeuw buitenlandse stemmen over het Nederlandse koloniale beleid
}

\section{G.J. SCHUTTE}

Er is de afgelopen honderd, honderdvijfentwintig jaar door heel wat buitenlandse auteurs aandacht geschonken aan het Nederlandse koloniale bezit en bestuur. Vooral aan zijn koloniën in Oost en West dankte het kleine, nauwelijks van natuurlijke rijkdommen voorziene Holland immers zijn betrekkelijk grote welvaart en positie als wereldmacht van de tweede rang. Bewondering, niet zelden vermengd met nauw verholen afgunst, maar ook zware kritiek viel de Hollandse koloniaal ten deel. Want wat in de era van het imperialisme als 'son patiënt et tenace effort de plusieurs siècles' werd geprezen ${ }^{1}$, heette in de jaren van de dekolonisatie 'lack of imagination and their national characteristic of stubbornness' Een beknopt overzicht van die buitenlandse stemmen over het Nederlandse koloniale beleid, de veranderingen in beeldvorming en waardering, de achtergronden en invloeden ervan, moet noodgedwongen selectief zijn. Daarom zal in het volgende alleen aandacht worden geschonken aan publikaties over het voormalige Aziatisch imperium. De Nederlandse expansie in het Atlantisch gebied vertoont daarmee immers naast overeenkomsten ook vrij wat verschillen, die meer bespreking zouden vergen dan hier als terloops gegeven kan worden. Beperking tot de Oost lijkt bovendien verantwoord, omdat daar naar algemene opvatting het Nederlandse kolonialisme zich in zijn belangwekkendste vormen voordeed en liet bestuderen. Een andere beperking die we ons hebben opgelegd is de uitsluiting van geschriften van Indonesiërs - zij kunnen immers ten aanzien van de geschiedenis van Nederlands-Indië evenmin als buitenstaanders worden beschouwd als hun Nederlandse collegae-historici. Overigens mag dit niet tot de conclusie leiden dat de wel als buitenlanders gekwalificeerde auteurs altijd vanuit een onbetrokken, onafhankelijke positie en optiek schreven. Alleen al het feit dat zij hun analyses en interpretaties op voornamelijk Nederlandstalige bronnen en studies moesten baseren, maakte dat onmogelijk. Niet zelden leunden zij in hoge mate

1. G. Angoulvant, Les Indes Néerlandaises. Leur rôle dans l'économie internationale (2 dln.; Parijs, 1926) I, xvi.

2. I. Chaudhry, The Indonesian Struggle (Lahore, 1950) 23. 


\section{G.J. SCHUTTE}

op zulke publikaties of op de bijstand en informatie van Nederlandse bestuursambtenaren, archivarissen en geleerden ${ }^{3}$. Die afhankelijkheid, hoe groot ook, sloot echter over het algemeen een zekere distantie en vooral een door eigen achtergronden gekleurde oordeelsvorming en waardering niet uit. Daarop zal in het volgende de nadruk vallen ${ }^{4}$.

Kort na de Mutiny van 1857 reisde de Brits-Indische advocaat J.W.B. Money naar Java. Hij trof er een samenleving aan, waar het goed toeven was:

Prosperity and contentment among the people, and good will between European and Native, united with a large revenue and surplus income for the state, were so exactly the requirements of India, that I anxiously inquired as to the means by which such ends were achieved. I was told that they were due to the culture system, to the government of the Natives through their old aristocracy, to the absence of competition between European and Native, to the distinctive privileges of the high Natives, and to the exalted prestige of the European ${ }^{5}$.

In Java, or, How to Manage a Colony (1861) toonde Money zich een enthousiast adept van Van den Bosch ${ }^{6}$. De Encyclopaedia Britannica ${ }^{1}$ mocht dan dicteren dat het cultuurstelsel door het eisen van gedwongen arbeid ten bate van nieuwe geïntroduceerde cultures schadelijk voor de algemene welvaart en dus voor de belastingheffing was, Money wist wel beter. In werkelijkheid had dat stelsel

3. Zo lijkt, om een voorbeeld te geven, de invloed van C. Lekkerkerker op Angoulvants boek groot te zijn geweest.

4. Uiteraard is voor het volgende gebruik gemaakt van de bestaande historiografische literatuur: D.G.E. Hall, ed., Historians of South East Asia (Londen, 1961); Soedjatmoko, An Introduction to Indonesian Historiography (Ithaca, 1965); J.S. Wigboldus, 'Historiografische introductie', in: D.H. Burger, Sociologisch-economische geschiedenis van Indonesia (Amsterdam, 1975) I, xv-lxxi; H.L. Wesseling, 'The Impact of Dutch Colonialism on European Imperialism' (ongepubliceerde paper Dutch-Indonesian Historical Conference, Ujung Pandang, 1978); H.L. Wesseling, ed., Expansion and Reaction (Leiden, 1978); P.C. Emmer en H.L. Wesseling, ed., Reappraisals in Overseas History (Leiden, 1979); W.Ph. Coolhaas en G.J. Schutte, A Critical Survey of Studies on Dutch Colonial History (Den Haag, 1980); L. Blussé en F. Gaastra, ed., Companies and Trade (Leiden, 1981); G.J. Schutte, 'De koloniale geschiedschrijving', in: W.W. Mijnhardt, ed., Kantelend geschiedbeeld. Nederlandse historiografie sinds 1945 (Utrecht, 1983) 289-310.

5. J.W.B. Money, Java, or, How to Manage a Colony. Showing a Practical Solution of the Questions now Affecting British India (2 dln.; Londen, 1861) I, 48.

6. Het werk was 'Dedicated to Memory of That Great Statesman, General Johannes van den Bosch, Governor-General and Commissary-General of the Dutch East Indies from 1830 tot 1834, author of the Java Culture System, the results of which are described in the following pages'.

7. In het artikel 'Java', deel 12, achtste druk (Money, Java, I, 298-299). 
multiplied and increased that private wealth which is the source of public income. It quadrupled the revenue, while easing the burdens on the people. And it converted the Native peasant's poverty into prosperity, and his habit of crime and laziness into industry and order ${ }^{8}$.

Elders voegde hij er nog aan toe dat tussen Javanen en Hollanders gevoelens van 'friendliness and mutual regard' bestonden'.

Volgens Money stemde het cultuurstelsel, omdat het zowel voordelig als rechtvaardig was, alle partijen tevreden. Anderen hadden met het dwangmatig karakter van het stelsel nog minder moeite. De Duitser Fr. von Hellwald erkende ronduit dat het op monopolie, gedwongen arbeid, patriarchaal despotisme en uitbuiting berustte. Hij verklaarde echter ongegeneerd sociaal Darwinistisch dat hogere culturen lagere met zulke methoden stap voor stap tot ontwikkeling moeten dwingen en daar ondertussen zelf ook beter van mogen worden ${ }^{10}$. Dit waren opvattingen die in het imperialistisch Europa van die dagen door velen in meerdere of mindere mate werden gedeeld. (Het laatste hiervoor gegeven citaat van Money wijst uit dat ook hem die gedachtengang niet vreemd was.) Boeken als van Money, de lofzang van A.R. Wallace op The Land of the Orang-Utan and the Bird of Paradise ${ }^{11}$ inspireerden avonturiers en empirebuilders van allerlei slag en standing $^{12}$. Droogstoppel werd om zijn florerende handel in koloniale waren zwaar benijd!

De aantrekkelijkheid van het Nederlandse koloniale model verdween niet toen het cultuurstelsel werd opgeheven. De afschaffing van de overheidsdwang, de grotere zorg voor de bevolking en ruimere ontplooiingskansen voor het individu vergrootten die eerder. Alom werd met bewondering naar het Hollandse koloniale bezit gekeken. Java leek immers een paradijselijke idylle. Dertig miljoen Javanen leefden en werkten er vreedzaam en tevreden, vergenoegd met het optreden van de koloniale heerser die de eenvoudigen beschermde en de aanzienlijken deel aan het bestuur gunde. De verbouw van tropische produkten voor de wereld-

8. Ibidem, 299.

9. Ibidem, II, 208-209.

10. Friedrich von Hellwald, Ueber Colonien und über die holländischen Niederlassungen in Ostindien insbesondere. Ein Beitrag zur niederländischen Colonialfrage (Wenen-Amsterdam, s.a. [omstreeks 1871-1872]).

11. A.R. Wallace, The Malay Archipelago. The Land of the Orang-Utan and the Bird of Paradise. A Narrative of Travel with Studies of Man and Nature (Londen, 1869, 7de dr. 1880).

12. Wesseling, Impact; A. van Marie, 'De rol van de buitenlandse avonturier', BMGN, LXXXV1 (1971) 32-39. 
markt maakte het tot een zeer aantrekkelijk bezit. Het was uniek wat een handjevol Nederlanders op 4000 mijl afstand van hun kleine, armelijke Nederland presteerde, meende de Fransman Chailley-Bert ${ }^{13}$.

Zijn landgenoot Cabaton deed niet in bewondering voor hem onder. Nederlands-Indië was niet slechts door de natuur rijk begiftigd, Nederlands bezittingen boden 'un rare exemple d'intelligence politique à la fois tenace et saga$\mathrm{ce}^{14}$. Het Nederlands-Indische bestuursstelsel vormde een voorbeeld waar de andere Europese kolonisatoren veel van zouden kunnen leren. De kern van die voorbeeldfunctie was natuurlijk gelegen in het relatieve gemak waarmee een zo rijk bezit werd beheerd. De bestuurlijke competentie van de Hollanders sprak vooral uit het feit, dat zij - anders dan bijvoorbeeld de Iberische kolonisatoren ${ }^{15}$ - in de grond van de zaak niet geïnteresseerd waren in het opleggen van hun eigen mentaliteit, cultuur en godsdienst; de inheemse bestuursvormen lieten zij in tact, zolang tenminste van geen verzet tegen hun heerschappij sprake was.

Het kon niet ontkend worden, aldus Cabaton, dat de Hollanders zich in voorgaande tijden wel eens hadden laten meeslepen door hun handelsgeest en winzucht. Behalve de VOC leverde vooral ook het cultuurstelsel daarvan een schrijnend voorbeeld. In blinde hebzucht had men zich toen overgegeven aan 'la plus gigantesque et immorale spoliation' en een miljoenen winst gerealiseerd 'a coups d'injustice, de légales exactions et de vies humaines' ${ }^{\prime 16}$. Maar die tijd was voorbij en sindsdien betoonde de Nederlands-Indische regering een algemene, haast moederlijk te noemen zorg voor de inheemse bevolking ${ }^{17}$.

In essentie was dat ook het oordeel van de Amerikaan Clive Day in diens The Policy and Administration of the Dutch in Java $(1904)^{18}$, decennia lang een gezaghebbend standaardwerk (voor de Leidse indologiestudenten was het verplichte lectuur ${ }^{19}$ ). Day's studie vormde een afrekening met het cultuurstelsel. Zijn oordeel daarover luidde kort en krachtig: 'The spirit of greed ruled the Dutch Government as it had ruled the East India Company ${ }^{\prime 20}$. Het stelsel ging van de fundamenteel onjuiste gedachte uit, dat de overheid het economisch welzijn van het individu beter kent dan het individu zelf; het zag voorbij aan de reeds door Adam Smith verwoorde wijsheid dat de functies van koopman en koning incom-

13. J. Chailley-Bert, Java et ses habitants (4de dr., Parijs, 1914; 1ste dr. 1900) 145 vlg.

14. A. Cabaton, Les Indes Néerlandaises (Parijs, 1910) 1.

15. Ibidem, 19.

16. Ibidem, 131, cf. 19-21.

17. Ibidem, 132 .

18. C. Day, The Policy and Administration of the Dutch in Java (New York, 1904).

19. Idem, The Policy and Administration of the Dutch in Java. With an Introduction by John Bastin (herdruk 1966, Kuala Lumpur-New York) vi.

20. Ibidem, 288. 
patibel zijn ${ }^{21}$. Day's verwerping van het cultuurstelsel was echter niet alleen op doctrinair liberalisme gebaseerd; een scherpzinnige analyse van de werking en effecten ervan bracht hem er ook toe. Hij beschouwde het cultuurstelsel als een voortzetting van het compagniesstelsel. Hij was bereid toe te geven dat de VOC 'greedy rather than cruel' was; 'it did not oppress the natives by design' ${ }^{22}$. Zo welwillend stond hij niet tegenover Van den Bosch en het cultuurstelsel: Van den Bosch sprak wel over de gunstige effecten van het stelsel voor de inheemse bevolking maar mag daarin niet serieus genomen worden. Winst maken, een batig saldo opbouwen waren het doel, en wie niet op de theorie maar de praktijk van het stelsel let, ziet hoe dat werd bereikt: er werd meer arbeid van de Javaan gevraagd dan nominaal was bepaald, de ene cultuur drukte zwaarder dan de andere, tal van (mislukte) teeltproeven kwamen ten laste van de Javaan, evenals de vervoerskosten van de cultuurprodukten; niet zelden werd ook nog eens landrente geheven. Als belastingstelsel was het cultuurstelsel onrechtvaardig, want het drukte niet overal even zwaar; als economisch stelsel werkte het averechts, want het fnuikte de arbeidslust van de Javanen en nekte de ontwikkeling van een particuliere ondernemersklasse; als sociaal systeem was het reactionair want het versterkte de positie van de aristocratie ${ }^{23}$. Het cultuurstelsel was dus au fond niets anders dan een 'system of forced labor' ${ }^{24}$, dat de Nederlandse schatkist miljoenen opleverde en de Javaanse samenleving verarmde.

Het spreekt vanzelf dat Day het liberale beleid van zijn dagen heel wat hoger waardeerde:

If the Dutch government deserves so much confidence to-day, it is because it has given up the kind of functions that the culture system thrust upon it, and has confined itself to what a government can properly $\mathrm{do}^{25}$.

Zijn uiteenzetting daarvan moet het Nederlands-Indische bestuur met redelijke dankbaarheid vervuld hebben. Day concludeerde dat van een redelijke bestuurszorg, van sociale en economische ontwikkeling gesproken mocht worden: 'measured by the Oriental Standard, or measured by their own past history, the Javanese are now comparatively well-to-do ${ }^{\prime 26}$ - en dat ondanks een geweldige bevolkingsgroei. Dat een en ander nauw samenhing met de eerbiediging en inschakeling van inheemse instellingen en gebruiken, stond daarbij voor Day ontwijfelbaar vast $^{27}$.

21. Ibidem, 122, 259-260.

22. Ibidem, 123 .

23. Ibideni, 255-300.

24. Ibidem, 273.

25. Ibidem, 339.

26. Ibidem, 381 .

27. Ibidem, 3, cf. 37. 
III

In de twintigste eeuw hield de buitenlandse waardering voor het Nederlandse koloniale model veelszins aan. In het bijzonder de economische ontwikkeling, die Nederlands-Indië tot 'un pays producteur de premier importance ${ }^{28}$ had doen worden, maakte indruk. Door iemand als Angoulvant, 'Gouverneur général honoraire des Colonies, Député de 1'Inde Francaise', werden honderden bladzijden aan de beschrijving van dat economische wonderwerk gewijd. De bijdrage van het gouvernement daaraan werd niet vergeten: irrigatieprojecten, proefstations, in het bijzonder de plantentuin te Buitenzorg, werden enthousiast en vol bewondering beschreven ${ }^{29}$. Veel belangstelling, in het bijzonder van Franse zijde, bestond er ook voor de bestuursinrichting, blijkens gedetailleerde overzichten van de Nederlands-Indische staatsinrichting, van opleiding, taken en werkwijze van het corps binnenlands bestuur $(\mathrm{BB})^{30}$.

Cabaton, Chailley-Bert (in de 'Introduction' tot de vierde druk van zijn Java uit 1914), Angoulvant, Bousquet ${ }^{31}$ - ze waren allen vol lof over de kwaliteit, toewijding en ijver van de Nederlands-Indische bestuursambtenaar. Een ijver die Bousquet zelfs wat te ver ging - hij bemoeide zich overal mee, tot in details en liet de Indonesiërs geen eigen verantwoordelijkheid. Het BB treedt op als de baboe van de bevolking, zo haalde hij Furnivall aan ${ }^{32}$. Tot dezelfde conclusie kwamen ook de Amerikanen Vandenbosch $(1934)^{33}$ en Emerson (1937) ${ }^{34}$.

Emerson, een Harvard assistant professor of government, vergeleek het Britse bestuur over Maleisië met het Nederlandse in Indonesië. Zijn uitgangspunt was dat

28. Angoulvant, Indes Neerlandaises, 1, 97.

29. Behalve door Angoulvant ook bijvoorbeeld door Chailley-Bert in de 'Introduction' tot de vierde uitgave uit 1914.

30. Zie behalve Chailley-Bert, Cabaton en Angoulvant; J. Chailley-Bert, Le recrutement des fonctionnaires coloniaux. La Hollande et les fonctionnaires des Indes Neerlandaises (Parijs, 1893); A.-E. Hückel, Etude d'Administration Coloniale Comparée. Les examens des administrateurs coloniaux. Les pensions des fonctionnaires civils aux Indes Neerlandaises. L'Académie Coloniale de La Haye (Hanoi-Haiphong, 1913); de auteur was Administrateur des Services Civils de 1'Indochine en gaf zijn overigens tamelijk zakelijke weergave als motto een citaat mee uit L. de Beauvoir, Java, Siam et Canton (2de dr., Parijs, 1869) 168: 'il n'existe pas dans le monde de corps administratif colonial réusissant autant d'instruction, de distinction, de capacité et de charme'. Zie ook E. Dubois, L'Education coloniale en Hollande (1909).

31. G.H. Bousquet, Lapolitique musulmane et coloniale des Pays-Bas (Parijs, 1938). Engelse uitgave Dutch Colonial Policy Through French Eyes (Londen-New York, 1940).

32. Bousquet, La politique musulmane, 88-89 onder verwijzing naar een voordracht van J .S. Furnivall in: Verhandelingen Indisch Genootschap (1934) 341.

33. A. Vandenbosch, The Dutch East Indies. lts Government, Problems, and Politics (3de dr., Berkeley-Los Angeles, 1942; 1ste dr. 1934) 154-155, 313.

34. R. Emerson, Malaysia. A Study in Direct and Indirect Rule (New York, 1937). 
in the present age the rationalism and universalism of the eighteenth century had given away to a disturbing consciousness of the original and constituting diversity of man ${ }^{35}$.

Hij prees de Nederlanders voor hun inzicht, 'that government should be built on institutions native to the soil ${ }^{136}$.

Tegenover de 'to its fullest potentialities' doorgevoerde 'indirect rule' in Nederlands-Indië stond hij echter ambivalent ${ }^{37}$. Enerzijds liet het de lokale culturen en tradities in hun waarde, beschermde ze tegen 'the onrush of westernizing improvements ${ }^{13}$. Anderzijds veroordeelde het de inheemse bestuurderen tot vegeteren 'in expensive idleness' ${ }^{139}$. Want meer dan de naam had het NederlandsIndische bestuursstelsel niet met indirect rule of dualisme gemeen: de zogenaamd zelfbesturende gebieden waren geen 'real native states governed by native authorities under European guidance and supervision' - het waren slechts 'variant forms of European colonial administration in which European officials make greater or less use of native instrumentalities ${ }^{10}$.

Het was de vraag natuurlijk in hoeverre dat echt betreurenswaardig was. Wat betekende het koloniale bestuur voor de modernisering en emancipatie van Indonesië? Na enig optellen en aftrekken kwam Emerson tot de conclusie dat het kolonialisme een noodzakelijke fase in de ontwikkeling van de betrokken volken was, een brugfunctie vervulde bij de overgang van 'Malaysian medievalism to the modern world ${ }^{41}$. Met die stelling verklaarde hij niet alleen de koloniale verhouding tenminste tijdelijk aanvaardbaar, ze diende hem ook als maatstaf om het actuele beleid van de koloniale heerser te meten. Naar de mate waarin deze zichzelf overbodig maakte, mocht hij geprezen worden. Op het krediet van de Nederlanders in Indonesië stond een groot aantal posten (economische en sociale modernisering, sociale wetgeving, verzwakking van de aristocratie en stimulering van de inheemse maatschappij, onderwijs) - al maakte Emerson daarbij de kanttekening dat langzamerhand ieder beseft 'that the contented cow produces more and better milk ${ }^{42}$.

Daar stond echter de fundamentele fout tegenover dat de koloniale regering de logische consequenties verwierp van de ontwikkelingen die ze zelf mee bevorderd had: de nationalistische beweging werd tegengewerkt en onderdrukt ${ }^{43}$.

35. Ibidem, 71.

36. Ibidem, 413.

37. Ibidem, 412.

38. Ibidem, 410.

39. Ibidem, 464.

40. Ibidem, 447.

41. Ibidem, 483.

42. Ibidem, 469.

43. Ibidem, 466, 521 
Dat er een ontwikkeling moest plaatsvinden waardoor de Indonesiërs - op grond van toegenomen ontwikkeling door Westerse educatie - meer verantwoordelijkheden zouden te dragen krijgen, werd, in ieder geval na 1901, door niemand meer betwist. De vraag was alleen in welk tempo en langs welke wegen die ontwikkeling zich moest voltrekken, en wat het einddoel ervan zou zijn. Voor Emerson was dat laatste een vrij en onafhankelijk Indonesië ${ }^{44}$. Waarschijnlijk bedoelde Vandenbosch met indonesianisatie hetzelfde. Hij legde echter de volle nadruk op de onhaalbaarheid daarvan in de overzienbare toekomst. Belangrijke voorwaarden als een maatschappelijke middenklasse, voldoende intellectueel geschoolden en bovenal nationale eenheid ontbraken immers ${ }^{45}$. Vandenbosch twijfelde er ook aan, of een unitarische staat moest worden nagestreefd. De dreiging van een Javaanse suprematie daarin zou stellig heftige reacties in de buitengewesten oproepen ${ }^{46}$.

Uitgesproken voorstanders van een gedecentraliseerde politieke ontwikkeling waren de Fransen Angoulvant en Bousquet. Naar hun mening was de instelling van de Volksraad veel te vroeg geschied. Eerst had men de politieke inschakeling van de bevolking op lokaal en regionaal niveau wortel moeten laten schieten en dan pas de kroon op het bouwwerk moeten plaatsen. Nu centraliseert de Volksraad de nationalistische tegenstander, aldus Bousquet ${ }^{47}$. Beiden toonden zich voorstanders van een associatiepolitiek die het moederland en een gemoderniseerde, door geneerlandiseerde Indonesiërs geleide kolonie blijvend zou bijeenhouden. Dat de Nederlanders daar zo weinig aan deden, verbaasde hen sterk; Bousquet toonde zich in dat verband haast geschokt door het feit dat de Nederlanders de betekenis van het Nederlands als lingua franca niet inzagen ${ }^{48}$. Hij meende trouwens ook dat de Nederlanders een grote vergissing maakten door de modernistische stromingen in de islam te favoriseren: orthodox of modernistisch, de moslim is anti-Westers en nationalistisch, stelde hij ${ }^{49}$.

IV

Vormden de studies van Vandenbosch, Emerson en ook Bousquet belangwekkende analyses van vooral de politieke kant van de koloniale samenleving, de in Birma werkzame Brit J.S. Furnivall richtte zich meer op de economisch-sociale

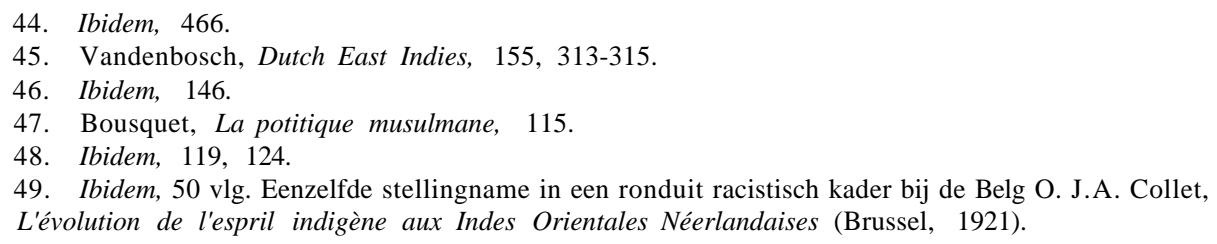

49. Ibidem, 50 vlg. Eenzelfde stellingname in een ronduit racistisch kader bij de Belg O. J.A. Collet, L'évolution de l'espril indigène aux Indes Orientales Néerlandaises (Brussel, 1921). 
grondslagen daarvan. Het voorwoord van zijn befaamd geworden Netherlands India. A Study of Plural Economy (1939) gaf zijn interesse en stellingname nauwkeurig aan:

This work attempts a study of the economie and social developments of Netherlands India, with especial reference to its Character as a Plural Society - a society in which distinct social orders live side by side, but separately, within the same political unit ${ }^{50}$.

Om het karakter en de werking van die Plural Society te beschrijven, greep Furnivall terug op haar ontstaansgeschiedenis. Hij kwam in dat verband tot opmerkelijke conclusies. Anders dan Raffles, die de Hollanders verweten had een spoor van vernieling en verwoesting nagelaten te hebben, constateerde hij dat het Compagniesbeleid van gedwongen leveranties en contingentering althans op het achttiende-eeuwse Java tot economische vooruitgang en bevolkingsgroei had geleid $^{51}$. Hetzelfde gold zijns inziens voor tenminste de eerste fase van het cultuurstelsel (tot 1840). Anders ook dan de liberale visie wilde doen geloven moest erkend worden, aldus Furnivall, dat 'the Culture System did in fact diffuse prosperity'; 'it brought millions more than before into the hands of the people $\mathrm{e}^{52}$.

Die materiële groei had echter ontwrichtend gewerkt op de sociale structuur. Door op de inheemse aristocratie te leunen, was deze onevenwichtig machtig geworden; de eenzijdige nadruk op de agrarische sector en het opleggen van gedwongen arbeid had de normale werking van de economie gefrustreerd en de bevolking economisch apathisch doen worden. Met verloop van tijd verwerd het cultuurstelsel dus van een stimulans tot een rem op de ontwikkeling ${ }^{53}$. De opvatting van de koloniale heersers over de Javanen sloot daarbij aan: Van den Bosch 'treated them like children, but like children that were mentally defective and would never grow up' ${ }^{54}$.

Het liberale beleid van vrij, individueel ondernemerschap had tegen de verwachtingen van de voorstanders in de Javaan echter ook niet economisch weerbaar gemaakt. In Netherlands India, en later nog eens in een tweede boek, Colonial Policy and Practice (1948), somde Furnivall de redenen daarvan op ${ }^{55}$. Ze kwamen er kortweg op neer, dat de wetmatigheden die een economische ontwikkeling kunnen veroorzaken in een koloniale context desastreuze sociale gevolgen heb-

50. J.S. Furnivall, Netherlands India. A Study of Plural Economy (2de dr., Cambridge, 1944; 1ste dr. 1939) Xv.

51. Ibidem, 41,42 .

52. Ibidem, 136, 135.

53. Ibidem, 145.

54. Ibidem, 141.

55. J.S. Furnivall, Colonial Policy and Practice. A Comparative Study of Burma and Netherlands India (New York, 1948), in het bijzonder 290-312. 
ben. Of men nu de inheemse bevolking zelf tot produktie voor de wereldmarkt stimuleert, dan wel ruim baan geeft aan Westerse ondernemingen die van goedkope inheemse arbeid gebruik maken, in beide gevallen is het resultaat het openbreken van de inheemse samenleving. Aanvankelijk moge de welvaart toenemen doordat zekere aan de inheemse maatschappij inherente nadelen worden opgeheven, weldra wordt die winst overtroffen door de maatschappelijke schade die de economische krachten aanrichten. Terwijl de behoefte aan geld voor de aanschaf van Westerse goederen groeit, heeft het marktmechanisme lage lonen en werkloosheid tot gevolg; waar de recrutering van arbeid via inheemse hoofden geschiedt komt daar nog eens bij dat zij hun traditionele machtsbasis verliezen en in plaats daarvan van de koloniale heerser afhankelijk worden.

Het resultaat van een en ander is de Plural Society. Deze kenmerkt zich door het dualisme van twee verschillende economische systemen, namelijk de stagnerende traditionele inheemse en daar overheen de Westers kapitalistische. Hand in hand hiermee gaat een maatschappelijk pluralisme, min of meer langs raciale lijnen; hoewel binnen eenzelfde staatsverband gesitueerd, leven de verschillende segmenten naast elkaar, elk met een eigen taal, cultuur, godsdienst en levenswijze. Elk der segmenten is economisch eenzijdig en sociaal onvolledig: de Europeaan is een passerende ondernemer, de inlander een landbouwer. Hun ontmoetingsplaats is de markt, economische mechanismen beheersen het geheel. Verbreking van dit wankele en ongezonde evenwicht zal maatschappelijke anarchie ten gevolge hebben - alleen een strikt doorgevoerd modern koloniaal beleid van ontwikkeling van de inheemsen kan tot langzame sociale reïntegratie en maatschappelijke gezondmaking leiden.

Furnivalls structurele ontleding van de anatomie van de koloniale samenleving vormde hoogte- en eindpunt van de vooroorlogse buitenlandse belangstelling voor het Nederlandse koloniale model tegelijk. Het vatte op het niveau van de gedistantieerde wetenschapsbeoefening allerlei daarin levende trends samen: de gebruikmaking van door Nederlanders aangedragen materiaal en modellen (in dit geval Boekes dualisme-these), het aanwijzen van de door (vroeger) Nederlands optreden veroorzaakte typisch koloniale scheefgroei, het geclausuleerd positieve eindoordeel, in het bijzonder over het Nederlands-Indische federalisme. Furnivall schreef zeker geen ode op het Nederlandse koloniale model. Zijn comparatistische aanpak en algemeen theoretische benadering, zijn beklemtonen van de onvermijdelijkheid van pijnlijke sociale begeleidingsverschijnselen van een onontkoombare economische modernisering, zijn benadrukken van het lang termijnkarakter van structurele verbeteringen en relatieve waardering voor aspecten van het recente Nederlandse beleid resulteerden echter in een eindoordeel waaraan een positief-waarderende tendens niet ontbrak. 
De tweede wereldoorlog en de daarop onder conflictueus geweld gevolgde dekolonisatie van Indonesië hebben de historiografie in allerlei opzicht diepgaand beïnvloed ${ }^{56}$. Het had in de eerste plaats een toename van de internationale belangstelling tot gevolg. Terwijl in Nederland de koloniale geschiedschrijving vrijwel tot stilstand kwam, ontwikkelde ze zich elders, in het bijzonder in de Verenigde Staten, tot een zeer florerend bedrijf. Tegelijkertijd werd ze methodisch en inhoudelijk vernieuwd. Het einde van het Da Gama-tijdvak ${ }^{57}$ en aanbreken van wat de eeuw van Azië leek te worden, leidde tot verandering van concepties en optiek. De Indonesiërs en hun geschiedenis kwamen centraal te staan; de koloniale periode leek slechts interessant als prehistorie van het contemporaine Indonesië. In principe afkeurenswaardig, in praktijk verschrikkelijk, was het koloniale tijdvak en beleid nog slechts interessant als negatieve stimulans voor de ontwikkeling van het Indonesisch nationalisme. Sterke invloeden uit politicologie, sociologie en antropologie veranderden zowel de methoden en concepten als de aandachtsvelden van deze nieuwere geschiedschrijving. Daar kwam nog bij een zekere standpuntkeuze, door Nederlanders wel als 'parti-pris' ervaren, soms gepaard met niet geheel toereikende kennis van Nederlandstalig bronnenmateriaal. Al met al kleurde dit de buitenlandse stemmen over het Nederlandse koloniale beleid, in recente maar ook in vroegere perioden, weinig positief.

Aanvankelijk was de aandacht vanzelfsprekend geconcentreerd op het Nederlands-Indonesisch conflict van de jaren 1945-1949. Dit gaf aanleiding tot zowel een reeks publikaties van bij dat conflict betrokkenen, als van voor informatieve doeleinden bestemde historische overzichten van wat vooraf ging. Bespreking van het eerste soort geschriften kan vanwege hun al te subjectieve karakter achterwege blijven; voor het tweede genre geldt iets soortgelijks, al varieerde de kwaliteit daarvan sterk en mag de invloed ervan niet onderschat worden.

Over het algemeen was de internationale reactie op Nederlands opstelling in de Indonesische kwestie negatief. Onbegrip voor de loop der geschiedenis, koloniaal eigenbelang en een onbegrijpelijke koppigheid waren standaardverwijten aan $\mathrm{Ne}-$ derlands adres. Die klonken ook door in de eerste, gedeeltelijk uit participerende observatie voortgekomen, belangrijke internationale analyse van de Indonesische revolutie, haar voorgeschiedenis en betekenis, Kahins Nationalism and Revoluti-

56. D.G.E. Hall, A History of South East Asia (Londen, 1955) vi.

57. K.M. Panikkar, Asia and the Western Dominance. A Survey of the Vasco da Gama Epoch of Asian History, 1498-1945 (Londen, 1953). 
on in Indonesia (1952)58. Hij schetste een in haar gevolgen voor de Indonesische samenleving nogal negatief beeld van de koloniale periode: de VOC-politiek had de Javaanse middenklasse laten verdwijnen, het feodaal despotisme versterkt en de boeren verarmd en tot landarbeiders in Hollandse dienst gereduceerd.

Ten tijde van het cultuurstelsel waren die tendensen alleen maar versterkt en daarna kon niet van een werkelijke verandering van de situatie gesproken worden. Het stelsel van Indirect Rule bevestigde het koloniaal gezag, het plurale karakter van de samenleving vormde een rem op de ontplooiing van het nationalisme. Dat was op zich de natuurlijke toevlucht van de maatschappelijk gefrustreerde, Westers geschoolde inheemse elite. De zeer beperkte mogelijkheden die het repressieve koloniale bewind hen liet, had voor 1942 een effectief samengaan van deze en andere anti-koloniale krachten (de islam, het platteland) in een sterke landswijde nationalistische beweging verhinderd. De Japanse bezetting bood die kans wel. De federalistische beweging, zoals die in Van Mooks deelstatenpolitiek vorm kreeg, had enig echt altruïstisch paternalisme en veel koloniaal eigenbelang als achtergrond. Het vervangen van de in 1949 overeengekomen federatieve staatsstructuur door een unitarische staat was 'natural and healthy. Indeed Indonesia would be politically and socially sick if this development had not taken place ${ }^{59}$; de federale structuur was een laatste restant Nederlands koloniaal dictaat dat de wil van de bevolking en de dynamiek van de revolutie ontkende. Afschaffing daarvan was voorwaarde voor de verdere opbouw in vrijheid en zelfstandigheid van de nieuwe, in vergelijking met de koloniale periode diepgaand gewijzigde Indonesische maatschappij.

Kahin was een trendsetter (ook letterlijk, vanwege zijn betrokkenheid bij het Cornell Modern Indonesia Project, bakermat van een reeks belangwekkende studies). Zijn werk was consistent en logisch; het verbond verleden en heden, sociologie, politicologie en geschiedenis. Het bevatte bovendien een verklaring voor de in vergelijking met voor 1942 grote kracht van de nationale beweging daarna en toonde, met meer kracht en vooral meer nadruk op het politieke aspect dan Furnivall had gedaan, de voosheid van de vooroorlogse koloniale samenleving aan.

De door Kahin uitgezette hoofdlijnen werden in de daarop volgende jaren nader ingevuld in een reeks van publikaties. Smail (1964) en Anderson (1972) beschreven gedetailleerd en nauwkeurig de beginperiode van de revolutie. Hun aandacht

58. G.McTurnan Kahin, Nationalism and Revolution in Indonesia (Ithaca, 1952); de auteur maakt melding van zijn verbijf in Indonesië 1948-1949.

59. Ibidem, 450 . 
ging daarbij speciaal uit naar de vrijheidsstrijd als sociale revolutie60. Andersons Java in a Time of Revolution is in het bijzonder bekend geworden. Het geeft een boeiende analyse van het verschijnsel pemuda en de rol van deze jongeren in de revolutie en van hun uitschakeling door politiek en sociaal gematigder krachten.

In The Crescent and the Rising Sun $(1958)^{61}$ beschreef Benda de rol van de islam als voertuig van het nationalisme niet alleen ten tijde van de Japanse bezetting, maar ook in de koloniale periode. Hij wees het koloniaal bewind aan als verantwoordelijk voor de groei van de santribeschaving: de inschakeling van de priyayi in het koloniale bestuursstelsel maakte hen tot handlangers van de christenen en vergrootte de kloof die hen scheidde van het volk: 'To peasants burdened with forced deliveries of produce, corvee labor and taxation, the man of God served as the only refuge and source of consolation' ${ }^{162}$. Vanuit deze ontleding van de driehoeksverhouding koloniaal bewind, priyayi en ulama kwam hij tot een nieuwe waardering van de ethische politiek en in het bijzonder de opvattingen van Snouck Hurgronje.

Uitgesproken negatief was Benda's oordeel over de indertijd veelal zo bewonderde Nederlandse eerbied voor het adatrecht. Hadden de ethici aanvankelijk tenminste nog een positieve doelstelling, na 1927 kwam daar een 'colorless, negative and defensive cours' voor in de plaats. 'Rust en Orde... were to guide policymakers in the closing years of Dutch rule ${ }^{\prime 63}$. De Leidse adatrechtschool leverde daar met zijn beklemtoning van de eigen aard van de Oosterse maatschappij en de noodzaak van geleidelijke, organische ontwikkeling een wetenschappelijke fundering voor.

In de inleiding tot een bronnenuitgave betreffende de communistische opstanden van 1926-1927 werd die klacht herhaald ${ }^{64}$. Ruth McVey leverde met The Rise of Indonesian Communism (1965) ${ }^{65}$ een verdere bijdrage, in de eerste plaats uiteraard tot de geschiedenis van de ontwikkeling van de nationalistische beweging, maar ook tot die van de koloniale politiek. Ze toonde aan dat de gebeurtenissen in 1926-1927 de houding van de koloniale overheid tegenover het nationalisme aanzienlijk verstrakten. De ethici en hun tolerantie tegenover de nationalistische beweging waren als het ware door de feiten gedesavoueerd. Ingleson, in zijn be-

60. John R.W. Smail, Bandung in the Early Revolution 1945-1946. A Study of the Social History of the Indonesian Revolution (Ithaca, 1964); Benedict R.O.G. Anderson, Java in a Time of Revolution. Occupation and Resistance, 1944-1946 (Ithaca, 1972).

61. Harry J. Benda, The Crescent and the Rising Sun. Indonesian Islam under the Japanese Occupation 1942-1945 (Den Haag-Bandung, 1958).

62. Ibidem, 16.

63. Ibidem, 60 .

64. Harry J. Benda en Ruth T. McVey, ed., The Communist Uprisings of 1926-1927 in Indonesia.

Key Documents (Ithaca, 1960).

65. Ruth T. McVey, The Rise of Indonesian Communism (Ithaca, 1965). 


\section{G.J. SCHUTTE}

schrijving van het ontstaan van de nieuwe nationalistische beweging daarna, heeft daar eveneens op gewezen ${ }^{66}$. Enerzijds resulteerde de repressie in interne factiestrijd en fragmentering van de tot de stedelijke intellectuele elite beperkte moderne nationalistische beweging, anderzijds in een sterke radicalisering daarvan. Zo ontstond een soort vicieuze spiraal. De machteloosheid van de nationalistische beweging in de jaren dertig verleidde de Nederlands-Indische regering te denken dat zij slechts een kleine, niet representatieve en machteloze groep vormde, aan wier verlangens men dus niet hoefde toe te geven. Dat deed de nationalisten weer wanhopen aan de concessiebereidheid van de Hollanders en radicaliseerde hen nog verder. Hun enige hoop was tenslotte een Pacific oorlog ${ }^{67}$.

VI

De in deze en andere studies ${ }^{68}$ verwoorde kritiek op het vooroorlogse koloniale beleid en op de naoorlogse reactie op de Indonesische revolutie heeft zeer bevruchtend gewerkt, de kennis verruimd, nieuwe visies en benaderingswijzen ingang doen vinden. De kritiek was echter soms wat fors getoonzet, hield niet altijd rekening met de omstandigheden, vertoonde wel eens enig ongeduld met de intenties van personen en maatregelen en ontkwam niet altijd aan op kennis van de afloop gebaseerde betweterigheid ${ }^{69}$. Een enigszins ideologisch gekleurd antikoloniaal en sociaal sentiment bracht auteurs als bijvoorbeeld Kahin, Anderson en McVey tot stellingen en analyses waaraan een zekere eenzijdigheid niet ontzegd kan worden. Distantie in tijd, het beschikbaar komen van archiefmateriaal

66. John Ingleson, Road to Exile: The Indonesian Nationalist Movement 1927-1934 (1ste dr., Singapore, 1979; 2de dr. 1980). Het is een vervolg op zijn studie over de nationalistische studentenvereniging: John Ingleson, Perhimpunan Indonesia and the Indonesian Nationalist Movement 1923-1928 (Melbourne, 1975).

67. De nationalistische beweging in de laatste vooroorlogse jaren is bestudeerd door Susan Abeyasekere, One Hand Clapping. Indonesian Nationalists and the Dutch 1939-1942 (Melbourne, 1976).

68. Verwezen moge nog worden naar het zeer kritische werk van R. von Albertini, Dekolonisation. Die Diskussion über Verwaltung und Zukunft der Koloniën 1919-1960 (Keulen, 1966); R. von Albertini en A. Wirz, Europaische Kolonialherrschaft 1880-1940 (Zürich, 1976) en voorts naar de verschillende stadia in de discussie vertolkende studies van J.D. Legge, Indonesia (Englewood Cliffs, 1964); B. Dahm, Sukarno and the Strugglefor Indonesian Independence (Ithaca, 1969); H.M. Federspiel, Persatuan Islam: Islamic Reform in Twentieth Century Indonesia (Ithaca, 1970); B. Dahm, History of Indonesia in the Twentieth Century (Londen, 1971); J.D. Legge, Sukarno. A Political Biography (Londen, 1972); A. Nagazumi, The Dawn of Indonesian Nationalism. The Early Years ofBudi Utomo, 1908-1918 (Tokyo, 1972). Een late, niet zeer geslaagde, vertegenwoordiger van het zeer kritische genre is A. van der Kraan, Lombok. Conquest, Colonization and Underdevelopment, 1870-1940 (Singapore, 1980).

69. De stelling van W.F. Wertheim ('Foreword' tot Benda, Crescent, viii): 'The historian who knows the end of the drama is better equipped to interpret the preceding acts' bergt - voorzover ze geen open deur intrapt - het gevaar van anachronisme in zich. 
missen sindsdien hun effect echter niet. Recente werken als Cheongs Van Mookbiografie, de monografieën van George en McMahon over de houding van Australië, respectievelijk de Verenigde Staten in het Nederlands-Indonesisch conflict, staan kritisch ook tegenover historiografische tradities en vertonen een genuanceerd, evenwichtig beeld; van een aantal overzichtswerken kan hetzelfde gezegd worden ${ }^{70}$. Die trend was trouwens reeds in 1960 ingezet met Van Niels boek over The Emergence of the Modern Indonesian Elite. Daarin werd bijvoorbeeld een lange verhandeling over de ethische politiek afgesloten met de zin: 'It was a sincere, honorably conceived vision of a great cultural and civilizing task'. Die constatering werd direct in perspectief gebracht door de toevoeging: 'In less than a decade the dream had dissolved ${ }^{71}$.

Ook de omstreeks 1925 ingevoerde nieuwe koloniale politiek die sterk leunde op de ideeën van Van Vollenhoven (adatrecht) en Boeke (dualistische economie) was naar Van Niels mening een naar zijn tijd en omstandigheden te beoordelen serieuze en allerminst conservatieve poging een antwoord te vinden op de moeilijke vraag hoe een koloniale samenleving te ontwikkelen. Ze weerspiegelde de toegenomen betekenis van de buitengewesten en wilde een uitweg bieden voor de door de ethici niet opgeloste problemen van de radicalisering van de inheemse beweging en de onvoldoende toegenomen levensstandaard. Dat de depressie na 1930 doorvoering ervan verhinderde, geeft nog niet het recht haar uitgangspunt als reactionair te typere ${ }^{72}$. Overigens is de aandacht de laatste tijd minder gericht op het koloniaal beleid, als wel op het feitelijk functioneren van de koloniale staat en de Nederlandse en Indonesische bestuursambtenaren daarin ${ }^{73}$.

VII

Van Niel behoort ook tot de leidende revisionisten van de geschiedenis van het cultuurstelsel, waarvoor in de jaren zeventig nieuwe belangstelling ontstond, na-

70. Y.M. Cheong, H.J. van Mook and Indonesian Independence. A Study in his Role in DutchIndonesian Relations, 1945-48 (Den Haag, 1982); M. George, Australia and the Indonesian Revolution (Melbourne, 1980); R.J. McMahon, Colonialism and Cold War. The United States and the Strugglefor Indonesian Independence 1945-1949 (Ithaca, 1981); D.K. Fieldhouse, The Colonial Empires. A Comparative Study from the Eighteenlh Century (Londen, 1966); H. Aveling, ed., The Development of Indonesian Society from the Coming of Islam to the Present Day (Sint Lucia, 1979); M.C. Ricklefs, A History of Modern Indonesia (Londen, 1981).

71. R. van Niel, The Emergence of the Modern Indonesian Elite (2de dr., Den Haag, 1970; 1ste dr. 1960) 100 .

72. Ibidem, 243-248.

73. H.A. Sutherland, Between Conflict and Accommodation (Amsterdam, 1977); H.A. Sutherland, The Making of a Bureaucratie Elite. The Colonial Transformation of the Javanese Priyayi (Singapore, 1979). 


\section{G.J. SCHUTTE}

dat iets eerder reeds enkele studies aan de voor een goed begrip van het stelsel belangrijke periode-Raffles waren gewijd ${ }^{74}$. Enigszins in het spoor van Furnivall is men over de oude, doctrinaire, moralistische en polemische visie (van Clive Day in het bijzonder dus) teruggekeerd naar de bronnen ${ }^{75}$. Alleen die maken het mogelijk uit te vinden hoe het stelsel werkelijk functioneerde, welke sociaaleconomische effecten het op de Javaanse maatschappij had. Tot nog toe is het niet mogelijk daarop met stelligheid te antwoorden - al geeft een citaat van Bastin en Benda misschien de trend aan. Zij vermelden achtereenvolgens de oude liberale veroordeling en Gerretsons boude stelling van het cultuurstelsel als Neerlands grootste geschenk aan Java en vervolgen dan:

There is probably much to be said for this latter view. At a time of rapid population growth in Java the Culture System undoubtedly placed large amounts of money in the hands of the people thereby enabling them to enjoy a higher Standard of living than would otherwise have been possible ${ }^{76}$.

Langzamerhand is wel duidelijk dat de term cultuurstelsel een veelheid aan zeer verschillende feitelijke situaties en effecten bemantelt. De druk van het stelsel op de bevolking was haast op geen twee plaatsen gelijk, niet elke misstand of hongersnood was eraan te wijten, het pastte veel minder bij de Javaanse traditie dan wel is beweerd, veroorzaakte maatschappelijke verschuivingen (zowel in de positie van de boer en de elite als in de functie van de desa), schakelde Java inderdaad in de wereldmarkteconomie in maar meer tot voordeel van de Europeanen dan de Javanen en valt, nogmaals, in dat alles niet als totaliteit te beschrijven.

De vernieuwde bestudering van het cultuurstelsel kan ook gezien worden als een

74. H.R.C. Wright, 'Muntinghe's Advice to Raffles on the Land Question in Java', BijdragenTaal-, Land- en Volkenkunde, CVIII (1952) 220-247; J. Bastin, The Development of Raffles' Ideas on the Land Rent System in Java and the Work of the Mackenzie Land Tenure Commission (Den Haag, 1954); J. Bastin, 'The Working of the Early Land Rent System in West-Java', Bijdragen Taal-, Landen Volkenkunde, CXVI (1960) 301-313.

75. R. vanNiel, 'Measurement of Change under the Culture System in Java, 1837-1851', Indonesia, XIV (1972) 88-109; R. van Niel, 'The Effect of Export Cultivations in Nineteenth-Century Java', Modern Asian Studies, XV (1981) 25-58; R.E. Elson, Sugar and Peasants. The Social Impact of the Western Sugar Industry on the Peasantry of the Pasuruan Area, East Java, from the Cultivation System to the Great Depression (Melbourne, 1979); R.E. Elson, 'Cane-burning in the Pasuruan Area: an Expression of Social Discontent', in: F. van Anrooy, ed., Between People and Statistics. Essays on Modern Indonesian History presented to P. Creutzberg (Den Haag, 1979) 219-233; R.E. Elson, 'Introduction', in: R. Fernando, Famine in Cirebon Residency in Java 1844-1850. A New Perspective on the Cultivation System (Melbourne, 1980). Een belangrijke Nederlandse bijdrage aan het debat over het cultuurstelsel is geleverd door C. Fasseur, Kultuurstelsel en koloniale baten. De Nederlandse exploitatie van Java 1840-1860 (Leiden, 1975).

76. J. Bastin en H.J. Benda, A History of Modern Southeast Asia. Colonialism, Nationalism, and Decolonization (Englewood Cliffs, 1968) 47. 
reactie op de bekende involutietheorie van C. Geertz77. Volgens Geertz was de periode 1830-1870 immers de beslissende, klassiek-koloniale fase waarin een autochtone landbouwmodernisering definitief gefrustreerd, de Javaan geproletariseerd en 'onherroepelijk op het spoor van een uitzichtloos agrarisch involutieproces gezet werd ${ }^{78}$. Geertz's indrukwekkende these wordt langzamerhand door steeds meer vraagtekens omgeven ${ }^{79}$. Dat opname in het koloniale verband ook anders uit kon werken heeft Fox in zijn Harvest of the Palm laten

$\operatorname{vin}$

In reactie op de tamelijk eenzijdige belangstelling van de naoorlogse geschiedschrijving voor de twintigste-eeuwse politieke ontwikkelingen, en wel op Java in het bijzonder, is, tenslotte, voor nog een tweetal velden van onderzoek hernieuwde belangstelling ontstaan. De aandacht richtte zich hierbij enerzijds op de buitengewesten, anderzijds op de VOC-periode. Ook deze regionale geschiedbeoefening is vernieuwd - gedekoloniseerd, zou men kunnen zeggen. De Indonesische samenleving staat in werk als van Fox, Andaya, Pelzer en anderen centraal ${ }^{81}$.

Ook in de meer politiek-diplomatieke regionaal-historische studies is de Indonesiër partij in eigen waarde geworden. Niet langer is hij object van een Europacentrische, koloniale benaderingswijze. Werd voorheen dit soort geschiedenis als het ware vanuit de Europese departementen van koloniën, vanuit koloniale hoofdsteden en de kapiteinshut van de kanonneerboot geschreven, auteurs als Irwin, Reid en anderen hebben de regio zelf als waarnemingspost gekozen ${ }^{82}$. De interactie van Indonesische en Europese krachten, de effecten van de kolonisatie

77. Clifford Geertz, Agricultural Involution. The Process of Ecological Change in Indonesia (Berkeley, 1963).

78. Ibidem, 52-82, met name 53.

79. Zie bijvoorbeeld B. White, 'Population, Involution and Employment in Rural Java', Development and Change, Vil (1976) 267-290; A. Polak, 'Agrarian Developments on Lombok. An Attempt to test Geertz' Concept of Agricultural Involution', Tropical Man, V (1976) 18-45; C. Fasseur en H. Baudet, 'Dévéloppement et stagnation en Insulinde aux 19e et 20e siècles', Itinerario (1980) 104-108; R.E. Elson, The Cullivation System and 'Agricultural Involution' (Melbourne, 1980).

80. J.J. Fox, Harvest of the Palm. Ecological Change in Eastern Indonesia (Cambridge, Mass., 1977).

81. L.Y. Andaya, The Kingdom of Johor, 1641-1728 (Kuala Lumpur, 1975); L.Y. Andaya, The Heritage of Arung Palakka (Den Haag, 1981); K.J. Pelzer, Planter and Peasant. Colonial Policy and the Agrarian Struggle in East Sumatra 1863-1947 (Den Haag, 1978); K.J. Pelzer, Planters against Peasants. The Agrarian Struggle in East Sumatra 1947-1958 (Den Haag, 1982).

82. G. Irwin, Nineteenth-Century Borneo. A Study in Diplomatic Rivalry (Den Haag, 1955); A. Reid, The Contest for North Sumatra. Atjeh, The Netherlands and Britain, 1858-1898 (New York, 1969). 
op de Indonesische samenleving krijgen de hoofdaandacht. Zulke studies zijn dus in de eerste plaats een bijdrage tot de geschiedenis van de betrokken regio, daarnaast geven ze ook een beter zicht op de feitelijke werking van de expansieen koloniale politiek.

IX

Soortgelijke ontwikkelingen hebben zich voorgedaan in de met hernieuwde aandacht bestudeerde geschiedenis van de VOC. Lange tijd werd de Compagnie sterk Indonesië-centrisch beschouwd: als voorfase van het cultuurstelsel. Dat had het zicht op de feitelijke aard van de maatschappij als Aziatische onderneming verloren doen gaan. Haar functioneren was bovendien te modern-imperialistisch geïnterpreteerd. Nederlandse studies uit de jaren dertig als van Mans velt en Van Leur vormden een aanzet tot herinterpretatie ${ }^{83}$. Pas na een intermezzo van enige decennia werd die draad echter weer opgenomen.

Baanbrekend werk verrichte K. Glamann met de publikatie van Dutch-Asiatic Trade 1620-1740 (1958) ${ }^{84}$. Deze rijk gedocumenteerde economische geschiedenis van wat in zijn tijd het belangrijkste handelslichaam ter wereld was verschafte in de eerste plaats inzicht in de bedrijfsorganisatie en de handelspolitiek van de VOC. Het analyseerde de handelsstromen in Azië, de ruil van Aziatische waren tegen goud en zilver uit Europa. Glamann vernietigde het oude beeld van de VOC als een

nearly historyless, evergreen pagoda-tree, whose golden fruits the Court of Directors had a monopoly of shaking into its turban at suitable intervals, from which it was only finally prevented by fraudulent, lazy, and incompetent officials ${ }^{85}$.

De Compagnie was in werkelijkheid daarentegen een redelijk goed geleid, hard werkende handelsfirma die scherp had te concurreren met Europese en Aziatische concurrenten op een steeds veranderende markt. Ze had geen monopolie en wel een ontwikkelingsgeschiedenis.

83. W.M.F. Mansvelt, Rechtsvorm en geldelijk beheer bij de VOC (Amsterdam, 1922); J.C. van Leur, Eenige beschouwingen betreffende den ouden Aziatischen handel (Middelburg, 1934) heruitgave in Indonesian Trade and Society. Essays in Asian Social and Economie History (Den Haag, 1955); hierin ook Van Leurs opstel over 'De 18e eeuw als categorie in de Aziatische geschiedenis' waarop gereageerd is onder anderen door A. Das Gupta, Indian Merchants and the Decline of Suratte (Wiesbaden, 1978); D. Rothermund, Europa und Asien im Zeitalter des Merkantilismus (Darmstadt, 1978); CR. Boxer, 'On the 18th century', Documentatieblad Werkgroep I8eEeuw, XLI-XLII (1979) 4-16. Zie voor het thema van de verhouding Europa-Azië en de rol der compagnieën daarin ook Blussé en Gaastra, Companies and Trade, en Wesseling, Expansion and Reaction.

84. K. Glamann, Dutch-Asiatic Trade 1620-1740 (Kopenhagen, 1958).

85. Ibidem, 265. 
De stelling dat de Compagnie geen grote revolutie in de Aziatische handel veroorzaakte, laat staan die beheerste of naar de hand zette, maar zich aan de daar heersende tradities en mogelijkheden veelszins aanpaste - oorspronkelijk opgeworpen door Van Leur, later uitgewerkt en gemoderniseerd door MeilinkRoelofsz - is vervolgens in een reeks van studies uitgewerkt, verfijnd en aangepast ${ }^{86}$. Steensgaard, zich concentrerend op de zeventiende eeuw, verklaarde het succes van de VOC (en andere Europese compagnieën) in de handel tussen Europa en Azië ten kostte van de overlandhandel en die der Portugezen uit hun institutioneel vernieuwende karakter ${ }^{87}$. Door de omvang van hun kapitaal, vloot en handelsvolume konden de compagnieën de protection costs beter in de hand houden. Dit betekende in feite dat de VOC zich kon verzekeren van een geregelde aanvoer van goederen tegen tamelijk stabiele prijzen; dit veroorzaakte weer een versterking van de oligopolistische markt- en prijsbeheersing in Europa.

Tot de geschiedenis van het functioneren van de VOC in Azië, de rivaliteit ook met Portugese, Engelse en andere concurrenten, hebben vooral ook CR. Boxer en $\mathrm{H}$. Furber belangrijke bijdragen geleverd ${ }^{88}$. Boxer - meester op vele wapens - vroeg ook hernieuwde aandacht voor de sociale geschiedenis van de VOC: het leven van de compagniesdienaren op haar schepen en factorijen. In Jan Compagnie in Japan $^{89}$ en andere studies wees hij op de intellectuele en culturele interactie tussen VOC-dienaren en hun Aziatische omgeving. Boxers studie van de factorij op Decima bevestigde voorts de flexibiliteit van de VOC, haar aanpassingsvermogen aan de lokale omstandigheden.

Daarop is ook gewezen in een reeks van studies over handel en wandel van de VOC in diverse delen van Azië. Voor een belangrijk deel zijn die studies geschreven door lokale geschiedschrijvers, met gebruikmaking van inheemse zowel als VOC-bronnen. Hoe uiteenlopend het werk van Raychaudhuri, Das Gupta, Prakash, Wills, Smith en anderen ${ }^{90}$ ook moge zijn, zij allen wijzen op het aanpas-

86. M.A.P. Meilink-Roelofsz, Asian Trade and European Influence in the Indonesian Archipelago between 1500 and about 1630 (Den Haag, 1962).

87. N. Steensgaard, Carracks, Caravans, and Companies (Kopenhagen, 1973), heruitgegeven onder de titel The Asian Trade Revolution of the Seventeenth Century. The East India Companies and the Decline of the Caravan Trade (Chicago, 1974).

88. CR. Boxer, The Dutch Seaborne Empire, 1600-1800 (Londen, 1965); CR. Boxer, Jan Compagnie in oorlog en vrede. Beknopte geschiedenis van de VOC (Bussum, 1977); een opgave van enkele van zijn andere publikaties in Coolhaas en Schutte, Critical Survey, 153; H. Furber, Rival Empires of Trade in the Oriënt 1600-1800 (Minneapolis, 1976).

89. CR. Boxer, Jan Compagnie in Japan 1600-1850 (2de dr., Den Haag, 1950; 1ste dr. 1936).

90. T. Raychaudhuri, Jan Company in Coromandel, 1605-1690. A Study in the Intenelations of European Commerce and Traditional Economics (Den Haag, 1962); A. Das Gupta, Malabar in Asian Trade, 1740-1800 (Cambridge, 1967); O. Prakash. The Dutch East India Company and the Economy of Bengal 1650-1718 (Delhi, 1967); J.E. Wills Jr., Pepper, Guns and Parleys, The Dutch East India Company and China, 1662-1681 (Cambridge, Mass., 1974); G.V. Smith, The Dutch in SeventeenthCentury Thailand (Dekalb, 1977); M.A.P. Meilink-Roelofsz, ed., De VOC in Azië (Bussum, 1976). 


\section{G.J. SCHUTTE}

singsvermogen van de Compagnie, op haar vermogen zich te voegen naar ter plaatse vigerende economische, politieke en sociale structuren. Wat Smith voor de VOC in Thailand constateerde, ging ook elders op: het succes van de Hollanders was gevolg van het feit dat 'they had learned to live 'within' the Tai system $^{\prime 91}$. Op het grootste deel van zijn werkterrein vertoonde Jan Compagnie dus een enigszins ander gedragspatroon dan op de Molukken, Java en Ceylon ${ }^{92}$, waar politieke hegemonie ten bate van economisch gewin ingeschakeld kon worden. Dat ook daar in allerlei opzichten van wederzijdse beïnvloeding sprake was, wordt echter steeds duidelijker.

\section{$\mathbf{X}$}

Het totaal van de buitenlandse stemmen over het Nederlandse koloniale beleid in de laatste eeuw grofweg resumerend mag, dunkt me, worden vastgesteld dat wat aanvankelijk een kakofonie leek, bij nader inzien zich onder de noemer van enkele themata en trends laat samenvatten.

De belangstelling was aanvankelijk vooral gericht op het thema der koloniale exploitatie. Men schreef voor of tegen het cultuurstelsel, over de indrukwekkende ontplooiing van de Nederlands-Indische bijdrage aan de wereldhandel sindsdien. In de laatste decennia van het koloniale tijdperk lag de nadruk meer op de sociaal-politieke aspecten daarvan. Nationalisme, kolonialisme en dekolonisatie vormden het centrale thema uit de jaren na 1945; pas in het laatste anderhalve decennium vindt een spreiding van de belangstelling naar diverse historische fasen - waaronder die van de VOC - en problematieken plaats. Men kan het voorgaande ook weergeven door erop te wijzen dat in de eerste drie perioden achtereenvolgens de thesen van Clive Day, Furnivall, Kahin en Geertz in de historiografische traditie centraal stonden.

Leken tweede wereldoorlog en dekolonisatie aanvankelijk waterscheidingen in de koloniale historiografie, recentelijk blijkt toch dat meer van continuïteit en aansluiting bij oudere tradities en aandachtsvelden gesproken moet worden. Het betreft echter nadrukkelijk een continuïteit in verandering. Deze tak van geschiedbeoefening is sinds 1945 onmiskenbaar ingrijpend gewijzigd. Er heeft, om te beginnen, een sterke internationalisering van haar beoefening plaats gevonden. De aanwending van sociologische, antropologische en sociaal-economische modellen en technieken heeft methodische vernieuwing en aandacht voor andere vel-

91. Smith, The Dutch, 46.

92. K.W. Goonewardena, The Foundation of Dutch Power in Ceylon, 1638-1658 (Amsterdam, 1958); S. Arasaratnam, Dutch Power in Ceylon, 1658-1687 (Amsterdam, 1958). 
den van onderzoek gebracht. De optiek is gewijzigd: de niet-Westerse samenleving is centraal komen te staan. Hedendaagse problematieken als (onderontwikkeling en de Noord-Zuidverhouding hebben de belangstelling gericht op de bedrijfsvoering van de VOC, de werking van cultuurstelsel en twintigsteeeuws koloniaal beheer, op hun economische, sociale en demografische effecten voor de Aziatische samenleving.

Het zal niet verbazen dat het beeld van de Hollandse koloniaal met deze ontwikkelingen mee veranderde. Money's gelukkige planter ${ }^{93}$ - een gentleman-farmer en vader voor zijn tevreden Javaanse werkvolk in een paradijselijke omgeving werd met verloop van tijd een energieke ondernemer die een benijdenswaardige economische ontwikkeling tot stand had gebracht, en vooral een degelijke, kundige, toegewijde en zorgzame bestuursambtenaar. Er waren natuurlijk ook anderen die klaagden over 'das schwache, arme, unterjochte Land, das so herrlich ist $^{194}$. Zij zagen in die ondernemer een dikbuikige, cultuur- en gevoelloze exploitant van geminachte goedkope Javaanse arbeidskrachten, een bittertjes drinkende, op zijn geld pochende bezoeker van de soos, een vloekende koeliedrijver die, dronken of niet, geen inlandse vrouw met rust liet. De bestuursambtenaar was voor hen op zijn best een pietepeuterige, bemoeizieke vertegenwoordiger van een kortzichtige, aan theoretiseren en plannenmaken overgegeven koloniale regering - het autoritaire werktuig van een behoudzuchtig, niet wezenlijk in de emancipatie der inheemse bevolking geïnteresseerd koloniaal bewind. Algemener ingang vond echter de terminologie zoals een Australisch journalist die in 1933 hanteerde. Hij schreef over de Indonesiërs als

obedient, tractable, little brown men leading a happy life in a fortunate world made for them by Nature, assisted ably by the methodical and omniscient Dutch Administration which provided a firm but benevolent rule ${ }^{95}$.

Na 1945 is zulke taal ondenkbaar, al wordt er nu weer genuanceerder geschreven dan in de jaren der dekolonisatie, toen de koppige, sluwe, tegendraadse, mooi pratende maar heel anders handelende Hollandse koloniaal zonder enige terughouding en op schrille toon 350 jaar koloniale uitbuiting en onderdrukking werd verweten.

Hoe men Droogstoppel dus in de loop der jaren ook portretteerde, steeds vertoonde zijn uiterlijk typisch stereotype kenmerken. De Fransman mocht de Hollandse koloniaal gebrek aan cultureel zendingsbewustzijn verwijten, de Amerikaan een teveel aan koloniale ideologie, de Brit zijn nooit geheel verstouw-

93. Money, Java, I, 33 vlg., II, 187 vlg.

94. Max Dauthendey, Erlebnisse auf Java (München, 1924) 25.

95. Aldus een weergave in George, Australia, 7-8. 


\section{G.J. SCHUTTE}

de vroeg-zeventiende-eeuwse nederlaag om de hegemonie in de Indonesische archipel ('Theis buterboxes are groanne soe insolent ${ }^{196}$ ) camoufleren met hooghartig vertoon van superioriteit - in feite ontliepen hun opvattingen elkaar niet veel, want omdat het Hollandse koloniale model, in zijn bloei zowel als in zijn ondergang, voorwerp van intense buitenlandse belangstelling vormde, stond Droogstoppel hoe dan ook immer exemplarisch voor de eigentijdse visies van de buitenlandse waarnemers op het kolonialisme.

96. Een dienaar van de Engelse Oostindische Compagnie in 1618, aangehaald door Furber, Rival Empires, 42. 


\section{Historiens étrangers et historiographie de l'expansion beige aux XIXe et XXe siècles*}

\section{DUMOULIN}

Traiter de la contribution des historiens étrangers à 1'historiographie de l'expansion de la Belgique aux XIXe et XXe siècles est une redoutable entreprise. Elle l'est d'une part parce qu'il est impossible de prétendre a l'exhaustivité et, d'autre part, et surtout, parce qu'on se heurte a une série de problèmes méthodologiques.

De ce dernier point de vue, il faut d'abord s'entendre sur la notion d'expansion. J. Stengers en a proposé une définition que nous adoptons. L'expansion de la Belgique 'est celle qui franchit les frontières. Tout ce qui a débordé les frontières du pays appartient à notre sujet ${ }^{1}$. Cette perspective suscite a son tour deux remarques. L'expansion entendue de maniere aussi large exige qu'on en dresse la typologie car ce qüi a débordé les frontières relève du politique, de l'économique, du social et du culturel. Ces différentes catégories s'organisent par ailleurs en amont et en aval d'une ligne de démarcation séparant l'expansion coloniale des autres formes de l'expansion.

Cette première distinction entre expansion coloniale et non coloniale ne résoud toutefois pas un deuxième type de problème. $\mathrm{Si}$, comme nous aurons 1'occasion d'y revenir, 1'historiographie de l'expansion beige - et plus particulièrement de l'expansion coloniale - s'inscrit dans la perspective européocentriste, il n'est un secret pour personne que depuis la décolonisation, des historiens se penchent davantage, voire exclusivement, sur les systemes economiques, sociaux, politiques et culturels des non-Européens ${ }^{2}$.

Tenant compte de ces observations, nous nous proposons d'envisager ici l'apport étranger à 1'historiographie de l'expansion beige en opérant une distinction entre les travaux consacrés a l'expansion non coloniale et ceux consacrés a l'ex-

* Je tiens a exprimer ici mes plus vifs remerciements a M. Jean-Luc Vellut qui a bien voulu me faire part de ses commentaires. Il va sans Ie dire que je porte seul la responsabilité du contenu du présent article.

1. J. Stengers, 'Introduction', Expansion belge 1831-1865 (Bruxelles, 1965) 5.

2. H.L. Wesseling - P.C. Emmer, 'What is Overseas History? Some Reflections on a Colloquium and a Problem', H.L. Wesseling, ed., Expansion and Reaction. Essays in European Expansion and Reaction in Asia and Africa (La Haye, 1978) 4. 